1 Fundação Oswaldo Cruz (Fiocruz), Escola Nacional de Saúde Pública Sergio Arouca (Ensp) - Rio de Janeiro (RJ), Brasil. Orcid: https://orcid. org/0000-0002-82841668

leonardodeberhardt@gmail. com

2 Universidade Federal do Rio de Janeiro (UFRJ), Instituto de Estudos em Saúde Coletiva (lesc) - Rio de Janeiro (RJ), Brasil. Orcid: https://orcid. org/0000-0002-19808558

gabriel@iesc.ufrj.br

${ }^{3}$ Fundação Oswaldo Cruz (Fiocruz), Escola Nacional de Saúde Pública Sergio Arouca (Ensp) - Rio de Janeiro (RJ), Brasil. Orcid: https://orcid. org/0000-0002-42201025

renato.bonfatti@gmail.com

4 Fundação Oswaldo Cruz (Fiocruz), Escola Nacional de Saúde Pública Sergio Arouca (Ensp) - Rio de Janeiro (RJ), Brasil.

Orcid: https://orcid org/0000-0002-0752-

7636

ary@fiocruz.br

\section{Imigração haitiana em Cascavel, Paraná: ponto de convergência entre história(s), trabalho e saúde}

\author{
Haitian immigration in Cascavel, Paraná: convergence point among \\ history(ies), work and health
}

Leonardo Dresch Eberhardt1, Gabriel Eduardo Schütz2 ${ }^{2}$, Renato José Bonfatti ${ }^{\mathbf{3}}$, Ary Carvalho de Miranda 4

DOI: 10.1590/0103-1104201811811

RESUMO O objetivo do estudo é analisar a relação entre trabalho e saúde dos imigrantes haitianos em Cascavel (PR), com foco na indústria frigorífica avícola. Para tanto, foi realizada pesquisa qualitativa, com três fontes de dados: entrevistas semiestruturadas (11), acordos coletivos de trabalho e notícias on-line. Os haitianos começaram a chegar a Cascavel em 2010 e se inseriram nas agroindústrias avícolas. Nas entrevistas, foram descritas diversas situações envolvidas na saúde do trabalhador, desde sintomas inespecíficos até acidentes de trabalho, além do racismo. Diante desse cenário, a comunidade haitiana tem procurado formas de resistência, por meio da Associação Haitiana de Cascavel e da participação nas igrejas locais.

PALAVRAS-CHAVE Trabalhadores. Saúde do trabalhador. Emigração e imigração. Saúde pública.

ABSTRACT The objective of the study is to analyze the relationship between work and health of Haitian immigrants in Cascavel (PR), focusing on poultry slaughtering industry. For this purpose, a qualitative research was carried out, with three data sources: semi-structured interviews (11), collective work agreements and online news. Haitians began arriving in Cascavel in 2010 and were inserted in the poultry agro-industries. In the interviews, various situations involved in the worker's health were described, from nonspecific symptoms to work accidents, in addition to racism. Within this setting, Haitian community have been looking for forms of resistance, through the Haitian Association of Cascavel and participation in local churches.

KEYWORDS Workers. Occupational health. Emigration and immigration. Public health. 


\section{Introdução}

A migração é um fenômeno, ao mesmo tempo, velho e novo. Está presente em praticamente toda a história da humanidade, mas se reveste de outros contornos e se renova em cada modo de produção e em cada fase de desenvolvimento no seu interior. A atual fase do capitalismo, caracterizada pela chamada 'reestruturação produtiva', está relacionada à reconfiguração da migração internacional ou transnacional, com um incremento substantivo dos fluxos migratórios'. O neoliberalismo e a financeirização da economia global vêm empurrando trabalhadores desempregados, em especial, os mais jovens, para ocupações desprotegidas e precárias, constituindo uma força de trabalho sub-remunerada e insegura em países periféricos ${ }^{2}$.

A Organização das Nações Unidas (ONU) afirma que havia 244 milhões de migrantes internacionais no ano de 2015. No Brasil, a cifra chega a 713 mil, representando menos de $1 \%$ da população do País ${ }^{3}$. O Brasil viveu um verdadeiro boom imigratório no início deste século, com quatro principais grupos de imigrantes, de acordo com os países de origem: (1) países centrais (Estados Unidos da América - EUA, Alemanha, Japão etc.), com força de trabalho qualificada; (2) países centrais largamente afetados pelas recentes crises do capitalismo e com laços migratórios com o Brasil (Portugal, Espanha e Itália); (3) países periféricos Sul-americanos (Argentina, Chile, Colômbia, Bolívia etc.); e (4) o Haiti, cuja imigração para o Brasil aumentou significativamente desde $2010^{4}$. Poderíamos, ainda, falar de um grupo considerável de imigrantes provenientes de países da África, do Oriente Médio e do Sul da Ásia. A população de imigrantes haitianos possui a particularidade de ser constituída, predominantemente, por pessoas negras e pobres que disputam seu lugar no mundo do trabalho com singular desvantagem competitiva, em virtude do racismo.

Em Cascavel, Paraná (PR), a presença de imigrantes haitianos passou a ser notória em finais de 2010, despertando o interesse de movimentos sociais e instituições acadêmicas locais. Esse fenômeno está estreitamente relacionado à indústria frigorífica: grande parte dos imigrantes que vieram a se estabelecer na cidade foi empregada por esse setor econômico ${ }^{5}$. Cabe ressaltar que o Oeste/Sudoeste do Paraná e o Oeste de Santa Catarina são as maiores regiões produtoras/ processadoras de carne de frango do País. O Brasil é, por sua vez, o maior exportador e o segundo maior produtor de carne de frango, em escala mundial6.

Diante desse cenário, o objetivo deste estudo é analisar a relação entre trabalho e saúde no caso dos imigrantes haitianos em Cascavel, com foco na indústria frigorífica de carne de frango. O município de Cascavel está localizado na região Oeste do estado do Paraná, conta com 316 mil habitantes e uma economia baseada na produção agropecuária e agroindustrial, além da prestação de serviços de saúde, educação e comércio.

Como a determinação social da saúde exige a compreensão histórica de seus fenômenos, sobretudo na relação entre produção e saúde ${ }^{7}$ é preciso olhar brevemente para o processo histórico do Haiti, desde antes de sua independência (em 1803/04) até os fatos que marcaram a recente diáspora do povo haitiano pelo mundo.

\section{Aspectos históricos do Haiti e a imigração para o Brasil}

"A história é um paradoxo andante. A contradição move-lhe as pernas"8(12). Qual exemplo melhor para os paradoxos e contradições invocados por Galeano do que a própria história haitiana?

O Haiti localiza-se na Ilha de São Domingos (também conhecida como Hispaniola), território dividido com a República Dominicana, no coração do mar do Caribe. Atualmente, possui, aproximadamente, 10 
milhões de habitantes. A Europa abriu seus olhos para a ilha em 1492, quando ali chegou Cristóvão Colombo. Cedida para a França no final do Século XVII e batizada de 'Saint Dominic', permaneceu uma próspera colônia até a década de 1790, quando explodiram as revoltas de escravos. O sistema produtivo implantado na ilha disseminou-se e ficou conhecido como plantation, que combinava a monocultura latifundiária de produtos tropicais para exportação e a utilização de força de trabalho escrava9,10.

As revoltas dos escravos atingiram tal grau de intensidade e organização que culminaram com a independência do Haiti frente ao governo francês, em 1804. Ganhava vida a primeira nação livre do continente americano: apesar de ser o segundo país a conquistar independência, foi o primeiro a abolir a escravidão. A revolução fora feita pelos negros outrora escravizados. Após a guerra pela independência, que dizimou mais de 160 mil pessoas, o Haiti sofreu com um bloqueio econômico capitaneado pelos EUA, que durou mais de 60 anos, e a recusa em reconhecer a independência do País, fato que só se concretizou com o pagamento de uma indenização à França, o que inviabilizou seu desenvolvimento econômico e social' ${ }^{10}$.

Em 1815, Simon Bolívar busca ajuda no Haiti para libertar os países da América continental. O governo haitiano lhe entregou navios, armamentos e soldados, sob uma única condição: libertar os escravos. No entanto, após a obtenção das vitórias, em 1826, o libertador convoca o Congresso do Panamá, buscando a integração da América Latina. Nem cogita a participação do Haiti. O espaço no Congresso fora reservado para convidados 'mais ilustres': EUA e Inglaterra ${ }^{10}$.

No século XX, a história haitiana foi marcada por frequentes intervenções estrangeiras, além de crises político-econômicas, revoltas sociais e desastres socioambientais. A marinha estadunidense permaneceu no País entre 1915 e 1934. O controle sobre a ilha permitia o acesso a grande parte da rota marítima caribenha. Em finais da década de 1950, o pretexto do governo estadunidense para a intervenção na ilha se tornou claro: possuir uma base de operações próxima a Cuba, que fez sua revolução socialista em 1959, e impedir sua difusão pela América Central e Caribe?.

Em 2004, a ONU instaura no País a Missão das Nações Unidas para Estabilização do Haiti (Minustah), liderada pelo Brasil, tornando o País o oásis da "indústria da ajuda internacional”10(22). Em 2010, a capital do Haiti, Porto Príncipe, foi surpreendida por um violento terremoto, que deixou mais de 200 mil mortos e 1,5 milhões de desabrigados. A magnitude do desastre foi potencializada pelas precárias condições de vida no País, considerado um dos mais pobres das Américas. Paradoxalmente, as péssimas condições sanitárias dos alojamentos da Minustah foram responsáveis pela introdução do vibrião do cólera, com epidemias importantes desde $2010^{10}$.

Essa sucessão de desastres socioambientais e crises político-econômicas ajuda a compreender a diáspora haitiana. $O$ Brasil passou a ser destino importante da imigração haitiana a partir de 2010. Em 2013, o Estado brasileiro começou a conceder visto humanitário aos haitianos, eliminando limites legais para a entrada no País.

A rota migratória inclui, comumente, viagem de avião para Equador, Peru ou Bolívia e entrada no Brasil via Brasiléia (Acre) e Tabatinga (Amazonas). Durante essas viagens, muitas vezes intermediadas por 'coiotes', os imigrantes, além de sofrerem muitas dificuldades, podem chegar a contrair dívidas de até U\$ 4.000,00. Há relatos de roubo, estupro, extorsão, agressão e abandono durante o trajeto. Mais recentemente, com a ampliação do acesso aos vistos concedidos pelo Estado brasileiro, muitos têm desembarcado em São Paulo"1.

Em cidades como Rio Branco, Porto Velho e Manaus, estabeleceu-se uma espécie de 'mercado' de força de trabalho haitiana, no qual empresários de todo o País 'escolhiam' seus futuros empregados ${ }^{12}$. Entre esses empresários, estavam alguns provenientes da região Oeste do Paraná. É assim que a história haitiana e sua diáspora atingem Cascavel. 


\section{Metodologia}

As relações entre a imigração de haitianos em Cascavel e as condições de trabalho nos frigoríficos avícolas foram estudadas numa perspectiva qualitativa, sob o ângulo das ciências sociais e humanas em saúde. O campo da saúde do trabalhador e o conceito de determinação social da saúde foram orientadores do percurso metodológico deste estudo ${ }^{7}$.

Foram utilizadas três fontes de dados: (1) entrevistas semiabertas realizadas com nove haitianos (oito homens e uma mulher, entre 20 e 43 anos de idade) e dois brasileiros (ambos do sexo masculino, com idade entre 49 e 50 anos); (2) notícias veiculadas pelo jornal local Central Gazeta de Notícias (CGN), entre 2014 e 2016; e (3) Acordos Coletivos de Trabalho (ACT) firmados entre sindicato e empresa frigorífica. A coleta de dados ocorreu entre junho e outubro de 2016.

A identificação e a seleção dos indivíduos a serem entrevistados foram pautadas com representantes da Igreja Anglicana local e da Associação Haitiana de Cascavel (AHC). O contato e a seleção dos sujeitos entrevistados foram inspirados no método da amostragem por bola-de-neve (snowball sampling) ${ }^{\mathbf{1 3}}$. As entrevistas foram realizadas em locais escolhidos pelos entrevistados, considerando a oportunidade para sua realização, por exemplo: no domicílio, nas dependências da AHC, na igreja, em locais públicos, na universidade etc. $\mathrm{O}$ roteiro das entrevistas incluiu quatro partes, cada uma com uma série de perguntas: (1) a vida no Haiti e a vinda para o Brasil; (2) o trabalho no frigorífico de aves; (3) o processo saúde-doença relacionado ao trabalho; e (4) movimentos sociais e atuação da AHC. A execução de entrevistas com dois brasileiros se justifica pela natureza exploratória do estudo: ambos acompanharam a inserção dos haitianos em Cascavel desde o início e, por isso, detinham informações sobre esse período. Enquanto os primeiros grupos de imigrantes já não residiam na cidade, os novos grupos não possuíam informações sobre o período inicial. O processo de análise das entrevistas incorporou contribuições da 'história oral'14.

As notícias analisadas foram buscadas no portal on-line da CGN com a palavra-chave 'haiti', que recuperou 160 resultados, publicados entre 2014 e 2016. Após leitura integral das notícias, foram incluídas 53 notícias que versavam sobre fatos envolvendo a comunidade haitiana de Cascavel. O material coletado foi tratado e analisado de forma crítica, levando em conta sua integração aos contextos social, cultural, político e ideológico ${ }^{15}$. Os ACT consultados estão disponíveis publicamente no site do Ministério do Trabalho e Emprego (MTE - Sistema Mediador) e foram firmados pela empresa frigorífica analisada e pelo sindicato correspondente entre 2008 e 2017.

A pesquisa foi apreciada e aprovada por Comitê de Ética em pesquisa (Parecer $\mathrm{n}^{\mathrm{o}}$ 1.500.148, de 14 de abril de 2016) e respeitou os preceitos éticos recomendados na pesquisa com seres humanos ${ }^{16}$. Perante o compromisso de manter o anonimato dos entrevistados, optamos pela utilização de pseudônimos. Os dois brasileiros receberam nomes comuns: João e José. Os haitianos, por outro lado, foram (re)nomeados a partir das personagens do romance 'L'Étranger' ('O Estrangeiro'), do escritor francês Albert Camus, publicado inicialmente em 1942 e que aborda questões envolvendo as relações sociais estabelecidas por um 'estrangeiro' (no sentido moral e ético) na comunidade argelina ${ }^{17}$.

\section{Resultados e discussão}

\section{A imigração haitiana atinge Cascavel, Paraná}

'Cascavel, cidade hospitaleira. Tu és fonte rica de labor. [...] És a sombra que acolhe o forasteiro'. Os versos do hino municipal de Cascavel revelam parte de sua história. Emancipada de Foz do Iguaçu, em 1962, a 
cidade recebeu distintos fluxos migratórios no século XX: gaúchos, catarinenses, paulistas, alemães, italianos etc. Acabou se tornando o centro político e econômico da região Oeste do Paraná.

Os haitianos começaram a chegar ali em 2010, atraídos por empresários locais, com a promessa de empregos em abundância e de qualidade - motivo apontado pelos entrevistados para o deslocamento de mais de 4 mil quilômetros.

Inicialmente, os haitianos foram inseridos na construção civil, em obras de ampliação de hospital e universidade locais. Findadas tais obras, permaneceram na região. A maior parte deles se integrou no trabalho em supermercados e em frigoríficos avícolas e, quando possível, trouxeram família e amigos. A comunidade foi crescendo: em 2014, estimava-se a presença de mais de 4 mil haitianos no local, com perspectiva de aumento nos próximos $a_{0}{ }^{5}$. Dados da Polícia Federal apontam que Cascavel está entre os 10 municípios brasileiros com mais haitianos regularmente registrados. O Paraná é o segundo estado brasileiro com maior população de haitianos (14,9\%), atrás apenas de São Paulo"1.

Em Cascavel, como em várias outras cidades do Brasil, os haitianos não foram recepcionados por organismos do Estado, mas por igrejas locais ${ }^{18}$. No caso em questão, foi a Igreja Anglicana que os recepcionou e concedeu apoio nas questões de moradia, trabalho, alimentação, além das espirituais. Eles acabam se concentrando em pequenas comunidades, em condomínios de quitinete - muito comuns em virtude da vida universitária da cidade - situados em bairros periféricos, suburbanos, dividindo as despesas e o espaço residencial com amigos ou familiares. Geralmente, estão longe da empresa em que trabalham e, por isso, usam com frequência o transporte público.

A questão da linguagem foi crucial. Muitos deles falam mais de uma língua: além do Kreyòl (conhecido no Brasil como 'crioulo'), língua nativa, dominam o francês e, em alguns casos, também o inglês e o espanhol. Muitos ainda não falavam o português com fluência, o que lhes causava muitas dificuldades. No período de coleta de dados, alunos do curso de letras da Universidade Estadual do Oeste do Paraná (Unioeste) se empenharam, voluntariamente, em ensinar português para os haitianos. Não houve qualquer apoio do poder público. As dificuldades eram imensas, não apenas pelos desafios da comunicação: os haitianos trabalham muito, não há tempo de sobra; mesmo os que estão desempregados - e não são poucos passam o dia todo na árdua e incessante tarefa da busca de emprego.

É preciso ressaltar que, apesar de nos referirmos aos 'haitianos' de maneira geral, não se trata de um grupo absolutamente homogêneo. Esse aspecto já havia sido apontado por pesquisadores e missionários durante trabalho de extensão com os haitianos em Brasiléia, no Acre ${ }^{19}$. Assim, existem diferenças no interior da comunidade, das quais apenas nos aproximamos de forma exploratória neste estudo. Algumas delas se referem, por exemplo, à qualificação profissional (alguns têm ensino superior completo, outros não concluíram o ensino básico) e à inserção laboral (alguns trabalham em linhas de produção, outros em cargos de gerência e outros estão subempregados ou desempregados). Essas diferenças nas condições de vida e trabalho impactam o processo saúde-doença. Mas, sobretudo, impactam a forma como esses indivíduos se percebem no interior da comunidade haitiana e como percebem a própria comunidade haitiana no interior da sociedade brasileira. Isso quer dizer que as entrevistas podem apresentar conteúdos por vezes contraditórios e conflituosos entre si.

\section{Relações entre trabalho e saúde a partir da experiência em um frigorífi- co de aves}

[...] cada entrevista possui um enredo próprio, tecido a partir de suas trajetórias no mundo do trabalho e da forma com que lidam com as experiências vividas ${ }^{20(314)}$. 
Foi essa premissa metodológica que guiou a realização das entrevistas, isto é, atentar para as peculiaridades de cada relato e, ao mesmo tempo, procurar compreender a experiência da comunidade haitiana como um todo.

Optamos por estudar o trabalho dos haitianos nos frigoríficos de aves por várias razões: (1) presença massiva de imigrantes nas indústrias frigoríficas da cidade; (2) importância do setor de abate e processamento de carnes para as economias local, regional e nacional; (3) necessidade metodológica de se debruçar sobre um setor específico da produção, em virtude do tempo curto disponível e da profundidade almejada.

Pesquisas realizadas em frigoríficos de aves descortinaram as várias etapas que o frango percorre enquanto é 'desmontado'. Cada uma dessas etapas possui alguns processos de trabalho específicos e, em decorrência disso, 'cargas de trabalho' específicas. Desde a chegada dos frangos à indústria, a linha principal de 'desmontagem' é a que segue: (1) descarregamento dos frangos dos caminhões e verificação do lote e das condições dos animais; (2) repouso dos frangos por cerca de duas horas antes da entrada na linha de produção; (3) choque de insensibilização em água corrente; (4) pendura, abate e sangria; (5) escaldagem em água fervente e depenagem com rolo giratório; (6) lavagem em chuveiros de aspersão; (7) evisceração; (8) espostejamento (desmonte da ave em seus diversos cortes); desossa; (9) embalagem, pesagem, etiquetagem, congelamento e armazenamento ${ }^{21-23}$.

A perspectiva de migrar para o Brasil trazia a promessa de empregos imediatos e de qualidade. A necessidade de pagar as dívidas contraídas na viagem e de enviar dinheiro para os familiares no Haiti, além da ameaça do desemprego, fizeram muitos haitianos aceitarem o trabalho pesado, intenso e desgastante dos frigoríficos. Masson (31 anos, desde 2013 no Brasil) explica por que se submete ao trabalho nesses locais: "Se você não trabalhar, como que você vai pagar aluguel, comida, onde você vai dormir? [...] Eu não quero dormir na rua, então eu trabalho".

Mersault, 29 anos e desde 2013 no Brasil, trabalhou por cinco meses no frigorífico de aves e optou por sair: "Foi meu primeiro emprego aqui no Brasil, e eu não gostei. Não gostei de trabalhar no frigorífico". Ele laborava na etapa final da linha de produção, chamada de 'embalagem final'. As tarefas envolviam a pesagem das 'peças' (como são chamados os pedaços cortados), sua embalagem, etiquetagem e armazenamento na câmara fria para congelamento e posterior destinação.

As cargas de trabalho envolviam o peso das caixas, a rapidez dos movimentos, o frio de temperaturas próximas a zero e a pressão da chefia:

A rapidez com que você tinha que fazer o trabaIho é que era ruim. Pra levantar uma caixa... Tudo bem, é legal, mas pra levantar com rapidez... Você tem que cuidar pra não cair. [...] o 'encarregado' é uma pessoa que é colocada ali pra ficar cuidando. Não é um supervisor. É um líder do grupo. É um trabalhador igual nós, mas fica como um chefe e incomoda mais que um supervisor. Ele não é haitiano, é brasileiro; às vezes, dava uma advertência pra pessoa por nada. (Mersault).

A rapidez exigida, a pressão da chefia e o frio constante, de acordo com os relatos dos entrevistados, também estão presentes em outros postos de trabalho, como os setores de espostejamento, de evisceração e de desossa. Tais cargas de trabalho produzem efeitos desgastantes nos trabalhadores. Um desses efeitos são as Lesões por Esforço Repetitivo (LER), muito frequentes entre operários de frigoríficos de aves ${ }^{24}$.

Casos de doença e acidentes de trabalho foram lembrados por Mersault. Destacase o caso de uma haitiana que teve o braço amputado. Tentou-se contato com ela, sem sucesso. Além disso, acidentes de trabalho envolvendo haitianos foram noticiados pela CGN, todos ligados à construção civil. 
Doença foi bastante. As pessoas não estão acostumadas com o frio. Quando havia muito frio, alguns ficavam resfriados. [...] De acidente, tiveram dois casos. Teve uma haitiana que perdeu um braço. Teve outro que 'entrou' na máquina que faz salsicha. A máquina pegou ele e ele ficou pendurado. Sorte que teve outro cara que viu e desligou a máquina, outro haitiano. Quebrou o braço e depois arrumou. Foi sorte dele. (Mersault).

Pérez (43 anos, desde 2014 no Brasil) relata a percepção que tem a respeito do serviço de medicina do trabalho da fábrica:

[...] um haitiano trabalhava numa máquina, a máquina pegou ele, agarrou e levou ele. Foi no médico e ele disse que era pra voltar trabalhar. [...] o monitor e o chefe não têm respeito pela saúde de ninguém. Se eu tô lá e me sinto mal, ele me diz pra esperar voltar pra casa. Tem gente que caiu na Coopavel ou ficou doente e não conseguiu mais trabalhar. Eles nos forçam pra trabalhar. A gente cai no chão, e não levam pro hospital. (Pérez).

Em pesquisa realizada em frigoríficos da região Oeste do Paraná, Bosi apontou que os serviços de medicina do trabalho e saúde ocupacional "tendem a compor um forte e articulado aparato político que auxilia a empresa a extrair todas as energias dos trabalhadores"20(318).

Os entrevistados relataram uma série de 'queixas', como dores nas mãos, braços e coluna; perda de sensibilidade tátil; fadiga; estresse; resfriados etc. Tais sintomas ainda não configuram doenças ocupacionais, mas já são indicativos da forma que assume a relação trabalho-saúde nos frigoríficos. Trata-se de sintomas inespecíficos, que poderiam ser enquadrados naquilo que Valla denominou "sofrimento difuso"25(41). Nas situações em que precisaram utilizar o serviço público de saúde de Cascavel, os haitianos disseram se sentir bem atendidos pelos profissionais de saúde. Com exceção da barreira linguística, os problemas por eles enfrentados ao precisarem de auxílio médico na rede pública parecem similares aos da população geral ${ }^{26}$.

Além das condições de trabalho, as jornadas de trabalho extensas ajudam a entender a ocorrência de acidentes, doenças e sintomas inespecíficos. Quase não há tempo para repouso; devido aos deslocamentos entre a residência e o trabalho e às horas extras, a jornada de trabalho pode chegar a 12 horas. Há, ainda, o tempo de deslocamento da entrada da empresa até o posto de trabalho, a troca de vestimentas e o preparo do instrumental. Segundo os entrevistados, isso poderia ocupar até 30 minutos. Entretanto, empresa e sindicato acordaram que apenas 10 minutos seriam computados como jornada de trabalho (cinco no início e cinco ao final). Dessa forma, o tempo de 'descanso' pode não ser suficiente para a reposição das energias físicas e psíquicas, provocando um desgaste permanente.

O salário, de cerca de $\mathrm{R} \$ 1.200,00$ mensais (sem deduções) não respondia às necessidades de sobrevivência dos haitianos. Tornava-se impossível enviar remessas de dinheiro para os familiares que permaneceram no Haiti, o que gerava sofrimento, estresse e insatisfação.

A pressão dos supervisores e encarregados sobre os trabalhadores levam Pérez a afirmar que "a gente é tratado como escravo". Masson, após algum tempo de entrevista, falou abertamente em racismo: "Tem muito chefe racista". Mais um paradoxo da história: a teoria pseudocientífica do eugenismo (racismo 'científico') ganhou força nos EUA e na Europa do Século XIX, justamente para legitimar a colonização da África e o uso de força de trabalho africana escravizada nas plantations do Caribe. Um eco do passado que ressoa no presente: o racismo acaba por dividir os trabalhadores, quebrar sua solidariedade e dificultar sua ação coletiva ${ }^{27}$.

Emmanuel (38 anos) chegou a Cascavel em janeiro de 2016 e, até a realização da entrevista, ainda não tinha conseguido emprego. Procurava trabalho diariamente, 
sem sucesso. Pensava em voltar ao Haiti ou migrar para outro país, mas não tinha dinheiro para tal. Muitos haitianos que viveram em Cascavel foram para o Chile, outros conseguiram voltar para o país de origem. Durante a entrevista de Masson, seu colega de quarto preparava as malas para o retorno. Também era trabalhador de frigorífico local. Ele embarcaria em Foz do Iguaçu naquela mesma noite para dar fim ao sonho brasileiro.

Essa questão não é peculiar aos haitianos: os trabalhadores da região Oeste do Paraná têm recusado o trabalho nos frigoríficos. Essa recusa aparece

justificada pelos trabalhadores pelos baixos salários e [...] difíceis e intoleráveis condições de trabalho, principalmente o ritmo das tarefas e as temperaturas frias em que os frangos são esquartejados 20(315).

A recusa dos trabalhadores diante dos empregos na indústria frigorífica pode ajudar a explicar a vinda de imigrantes haitianos para o trabalho nesses locais.

\section{Formas de resistência e apoio social}

Além da recusa ao trabalho nos frigoríficos, os haitianos têm buscado outras formas de resistência. Mesmo que sutis e difusas, essas resistências têm tido importância fundamental.

Em primeiro lugar, a relação dos haitianos que trabalham na empresa estudada com o sindicato que os representa legalmente é frágil e controversa. Masson afirmou que "O sindicato não faz nada, nada, nada pra nós [haitianos]". E Celeste (20 anos, em Cascavel desde 2016): "Até pago a taxa [mas] nunca fui ao sindicato". Procurado durante o trabalho de campo, um dirigente sindical afirmou não ter nenhum cuidado especial com a comunidade haitiana sob sua representação. Para ele, trata-se de trabalhadores como quaisquer outros.

Em segundo lugar, uma forma importante de resistência desse grupo social se dá por meio da espiritualidade. A comunidade haitiana de Cascavel tem grande apreço pelas igrejas locais, de diversas religiões. Entre elas, tem destaque a Igreja Anglicana, que auxiliou os imigrantes desde a chegada à cidade. Mersault baliza a relevância desse ponto: "as igrejas são as que mais ajudam". Elas concedem o chamado apoio social, que consiste em ajuda material, lazer, conforto, cultura e esperança. Em muitos casos, a igreja é um dos únicos locais onde grupos de haitianos e de brasileiros estabelecem relações de solidariedade e confiança ${ }^{25}$.

Por fim, a AHC também pode ser entendida no quadro conceitual do 'apoio social'. Fundada, inicialmente, em 2014 e retomada em 2016, a AHC pretende defender os interesses da comunidade haitiana frente à sociedade cascavelense e o poder público municipal. Entre suas ações, destacam-se a confecção de uma cartilha de orientações para os haitianos recém-chegados (em conjunto com vereador local), um levantamento sociodemográfico da população haitiana local (em conjunto com a igreja anglicana e pesquisadores), a organização de eventos comemorativos em datas importantes no Haiti e a criação de um programa de rádio transmitido via internet, que pode ser acessado do país caribenho.

A atuação da AHC em espaços políticos é ainda muito limitada. Isso não desmerece sua importância para a comunidade. É preciso lembrar, pois, que

[...] as formas difusas de ação constituem o terreno onde se formam as referências capazes de sustentar a agregação em torno de ideias e projetos coletivos. Nessa perspectiva, a ação organizada, na sua forma mais institucionalizada, é parte de um processo mais longevo de produção das experiências coletivas que a antecedem, alimentam e atravessam, fornecendo seus conteúdos, suas formas e suas motivações $28(24)$

Celeste, por exemplo, afirmou que seus 
únicos momentos de lazer e diversão são oportunizados pela igreja que frequenta e pela AHC. Ao destacarem as 'festas' e os 'amigos' proporcionados por essas instituições, os entrevistados trazem à tona uma dimensão importante da organização coletiva, isto é, a possibilidade de construir laços de amizade e de solidariedade, de viver a vida, apesar das adversidades que enfrentam cotidianamente. $\mathrm{O}$ apoio social, portanto, pode servir, também, para o alívio do desgaste acumulado pelo trabalho.

Existem outras experiências de organização coletiva de haitianos pelo Brasil. Uma delas é da Kore Ayisyen (Ajudar Haitianos), de Contagem, em Minas Gerais ${ }^{29}$. Além disso, os haitianos estão organizados em âmbito nacional pela Organização dos Haitianos que Vivem no Brasil (OHVB).

Um importante entrave para as associações de haitianos é a legislação brasileira. O Estatuto do Estrangeiro ${ }^{30}$, criado na época da ditadura militar, considera os imigrantes como cidadãos de segunda classe, perigosos e vulneráveis, e proíbe sua organização política ${ }^{29}$.

\section{Considerações finais}

"Os cientistas dizem que os humanos são feitos de átomos. Mas a mim um passarinho contou que somos feitos de histórias"31(1). Durante a pesquisa, acompanhamos um pouco da história dos haitianos que vivem em Cascavel (PR). Fazem parte dela a história do próprio Haiti, a história da imigração para o Brasil, a história de Cascavel e, por fim, a história que a comunidade haitiana vem construindo desde 2010.

A imigração haitiana em Cascavel constitui um ponto de convergência entre a(s) história(s), o trabalho e a saúde. Feitos de histórias, os haitianos são classe trabalhadora. Mas também são feitos de átomos: a implicação dessa condição histórica nos seus corpos se manifesta nos 'sintomas difusos' que relatam, revelando um acúmulo de desgaste. $\mathrm{O}$ apoio social proporcionado pela AHC e pelas igrejas locais é importante, não apenas na medida em que alivia o desgaste, mas, também, por proporcionar um espaço de solidariedade, ponto crucial para a ação coletiva.

Entre os pontos levantados pelo estudo que carecem de aprofundamento, destaca-se, por exemplo, a questão da mulher haitiana. Como apontam entidades sindicais, as mulheres negras trabalhadoras são triplamente discriminadas - por etnia, gênero e classe social - e "ocupam a posição mais vulnerável no mercado de trabalho e na sociedade"32(12). Durante a coleta de dados, conseguimos ter acesso à entrevista com apenas uma mulher haitiana, Celeste, de modo que não foi possível adentrar as questões de gênero com maior profundidade. Essa questão pode ser objeto de estudos futuros que pesquisem as comunidades haitianas, não só em Cascavel, mas em todo Brasil.

Por fim, a saúde do trabalhador e a saúde pública precisam estar atentas à imigração para consolidá-la como um objeto de estudo no interior de seus campos de conhecimento e ação. Isso significa compreender o processo saúde-doença como situado historicamente.

Essa história, contudo, não acaba aqui. Ela continuará a se desenvolver, assim como os paradoxos e contradições no seu interior. Não de forma autônoma ou automática, mas a partir das relações sociais estabelecidas pelos sujeitos, grupos e classes sociais. 


\section{Referências}

1. Baeninger R. Migração transnacional: elementos teóricos para o debate. In: Baeninger R, Peres R, Fernandes D, et al., organizadores. Imigração haitiana no Brasil. Jundiaí: Paco Editorial; 2016. p. 13-43.

2. Braga R. A rebeldia do precariado: trabalho e neoliberalismo no Sul global. São Paulo: Boitempo; 2017.

3. United Nations. Department of Economical and Social Affairs. International migration report 2015. New York: UN; 2016.

4. Uebel RRG. Aspectos gerais da dinâmica imigratória no Brasil no Século XXI. In: Anais do $1^{\circ}$ Seminário Migrações Internacionais, Refúgio e Políticas. São Paulo: Unicamp; 2016.

5. Martins JRV. A diáspora haitiana: da utopia à realidade. Foz do Iguaçu: Unila; 2014.

6. Associação Brasileira de Proteína Animal. Relatório Anual 2016 [internet]. São Paulo: ABPA; 2016 [acesso em 2016 nov 21]. Disponível em: http://abpa-br. com.br/.

7. Laurell AC, Noriega M. Processo de produção e saúde: trabalho e desgaste operário. São Paulo: Hucitec; 1989.

8. Galeano E. La paradoja andante [internet]. Argentina: Página 12; 2007 [acesso em 2017 jan 10]. Disponível em: https://www.paginal2.com.ar/diario/sociedad/3-96843-2007-12-30.html.

9. Pechanski JA. Haiti. In: Sader E, Jinkings I, organizadores. Latinoamericana: Enciclopédia contemporânea da América Latina e do Caribe. São Paulo: Boitempo; Rio de Janeiro: UERJ; 2006.

10. Seitenfus R. Haiti: dilemas e fracassos internacionais. Ijuí: Unijuí; 2014.

11. Fernandes D, Faria AV. A diáspora haitiana no Brasil: processo de entrada, características e perfil. In: Baeninger R, Peres R, Fernandes D, et al., organiza- dores. Imigração haitiana no Brasil. Jundiaí: Paco Editorial; 2016.

12. Paula EA. Entre desastres e transgressões. A chegada dos imigrantes haitianos no Reino deste mundo Amazônico. Novos Cadernos NAEA [internet]. 2013 dez [acesso em 2018 fev 15]; 16(2):187-206. Disponível em: http://www.periodicos.ufpa.br/index.php/ ncn/article/view/1124.

13. Atkinson R, Flint J. Accessing hidden and hard-to-reach populations: snowball research strategies. Social research update [internet]. 2001 [acesso em 2016 mar 5]; 33:1-4. Disponível em: http://sru.soc. surrey.ac.uk/SRU33.html.

14. Joutard R. Desafios à história oral do século XXI. In: Ferreira MM, Fernandes TM, Alberti V, organizadores. História oral: desafios para o século XXI. Rio de Janeiro: Fiocruz; 2000.

15. Schwartz R. Mídia e história: registros, documentos e fontes. Jornal Alcar [internet]. 2012 [acesso em 2018 fev 15]; 2:1-5. Disponível em: http://www. ufrgs.br/alcar/jornal-alcar-no-2-maio-de-2012/ Midia\%20e\%20Historia.pdf/view.

16. Brasil. Conselho Nacional de Saúde. Resolução no 510, de 7 de abril de 2016. Diário Oficial da União. 24 maio 2016

17. Camus A. O estrangeiro. Record: São Paulo; 1979.

18. Oliveira ACV, Moreira PG. Os imigrantes ilegais da Colômbia, Bolívia e Haiti no Brasil: considerações do ponto de vista da Segurança Internacional. Mural Internacional [internet]. 2013 jul-dez [acesso em 2018 fev 15]; 4(2):63-71. Disponível em: http:// www.e-publicacoes.uerj.br/index.php/muralinternacional/article/view/8370/0.

19. Cotinguiba GC, Pimentel M, Travessini OM, et al. Relatório Haitianos Brasiléia - Acre [internet]. Porto Velho: UNIR; 2013 [acesso em 2018 fev 15]. Disponível em: http://haitiaqui.provisorio.ws/wordpress/ 
wp-content/uploads/2016/10/PIMENTEL-M.L.-COTINGUIBA-G.-C.-2013-Relat\%C3\%B3rio-Haitianos-em-Brasil\%C3\%A9ia.pdf.

20. Bosi AP. A recusa do trabalho em frigoríficos no oeste paranaense (1990-2010): a cultura da classe. Diálogos [internet]. 2013 jan-abr [acesso em 2016 abr 25]; 17(1):309-335. Disponível em: http://ojs. uem.br/ojs/index.php/Dialogos/article/downlo$\mathrm{ad} / 36045 / 18656$

21. Sarcinelli MF, Venturini KS, Silva LC. Abate de aves: Boletim Técnico. Vitória: UFES; 2007.

22. Murofuse NT, Cêa GSS, Carvalho M, et al. Cartilha sobre saúde do trabalhador: fique de olho para não entrar numa fria! Cartilha para trabalhadores de frigoríficos. Cascavel: Unioeste, 2008.

23. Neli MA, Navarro VL. Reestruturação produtiva e saúde dos trabalhadores na agroindústria avícola no Brasil: o caso dos trabalhadores de uma unidade produtiva de abate e processamento de aves. In: Antunes R, organizador. Riqueza e miséria do trabalho no Brasil II. São Paulo: Boitempo; 2013.

24. Heck FM. Uma geografia da degradação do trabalho: o adoecimento dos trabalhadores em frigoríficos. Percurso [internet]. 2013 [acesso em $2018 \mathrm{fev}$ 15]; 5(1):3-31. Disponível em: http://ojs.uem.br/laboratorio/ojs/index.php/Percurso/article/viewFile/19066/11309.

25. Valla VV. Globalização e saúde no Brasil: a busca da sobrevivência pelas classes populares via questão religiosa. In: Vasconcelos EM, organizador. A saúde nas palavras e nos gestos. São Paulo: Hucitec; 2001.

26. Viegas APB, Carmo RF, Luz ZMP. Fatores que influenciam o acesso aos serviços de saúde na visão de profissionais e usuários de uma unida- de básica de referência. Saúde Soc [internet]. 2015 [acesso em 2018 fev 15]; 24(1):100-112. Disponível em: http://www.scielo.br/scielo.php?script=sci arttext\&pid=S0104-12902015000100100\&lng=en\& $\mathrm{nrm}=$ iso\&tlng=pt.

27. Callinicos A. Capitalismo e racismo. São Paulo: Zahar; 2000.

28. Algebaile E, Valla VV. Classes populares no Brasil: uma pauta de questões no tempo. In: Valla VV, Algebaile E, Guimarães MB, organizadores. Classes populares no Brasil: exercícios de compreensão. Rio de Janeiro: Fiocruz; 2011.

29. Barros CR, Rosa DD, George P. Processos de participação e organização política de haitianos no Brasil: experiências e desafios da Kore Ayisyen (Associação dos Haitianos de Contagem/MG). In: Anais do $1^{\circ}$ Seminário Migrações Internacionais, Refúgio e Políticas. São Paulo: Unicamp; 2016.

30. Brasil. Lei no 6.815, de 19 de agosto de 1980. Define a situação jurídica do estrangeiro no Brasil, cria o Conselho Nacional de Imigração, e dá outras providências. Diário Oficial da União. 21 ago 1980.

31. Galeano E. Entrevista: Galeano fala sobre O Filho dos Dias, um livro em que cada dia nasce uma história. Porto Alegre: L\&PM; 2013 [acesso em 2016 jan 10]. Disponível em: http://www.lpm.com.br/.

32. Sindicato dos Metalúrgicos de Campinas e Região. Mulher negra: tripla discriminação. Rev. Resistência. $2013 ; 12-13$.

Recebido em 19/02/2018

Aprovado em 08/07/2018

Conflito de interesses: inexistente

Suporte financeiro: Bolsa de estudos (Mestrado em Saúde

Pública) concedida pela Fundação Carlos Chagas Filho de Amparo

à Pesquisa do Estado do Rio de Janeiro (Faperj) 